\title{
Pedagogias críticas latinoamericanas y filosofía de la liberación: potencialidades de un diálogo teórico-político
}

\author{
Jorge Fabián Cabaluz-Ducasse
}

Universidad Academia de Humanismo

Cristiano, Chile

fabiancabaluz@gmail.com

\section{Resumen}

El artículo propone impulsar un diálogo ético, politico, epistemológico y conceptual de largo alcance entre la Filosofía de la Liberación (elaborada por Enrique Dussel) y las Pedagogías Críticas Latinoamericanas. Preocupado por fortalecer las vertientes críticas que configuran el campo pedagógico, el artículo se refiere inicialmente a las potencialidades teóricas de desplegar un ejercicio dialógico entre las corrientes señaladas. El artículo reflexiona en torno a tres grandes puntos de encuentro o de articulación, a saber: la praxis de liberación, el posicionamiento desde América Latina y las alteridades oprimidas, y la descolonización epistemológica. Finalmente, se refiere a la relevancia de los conceptos de liberación, alteridad y colonialidad para el devenir de las Pedagogías Críticas Latinoamericanas del siglo XXI.

\section{Palabras clave}

Teoría de la educación; pedagogía critica; filosofía de la liberación; educación politica; Latinoamérica (Fuente: Tesauro de la Unesco).

Recepción: 10-02-2015 | Envío a pares: 13-10-2015 | Aceptación: 07-12-2015 | Aprobación: 14-12-2015 


\title{
Latin American Critical Pedagogies and the Philosophy of Liberation: The Potential of a Theoretical-Political Dialogue
}

\begin{abstract}
The intent of this article is to encourage a far-reaching ethical, political, epistemological and conceptual dialogue between the philosophy of liberation (as expounded by Enrique Dussel) and Latin American critical pedagogies. Concerned about strengthening the critical aspects that shape the field of education, it refers initially to the theoretical potential of deploying a dialogic exercise between these currents of thought. Three major points of encounter are considered; namely: the praxis of liberation, positioning from the standpoint of Latin America and the oppressed otherness, and epistemological decolonization. The article also refers to the relevance of the concepts of liberation, otherness and colonialism for the future of Latin American critical pedagogies in the twenty-first century.
\end{abstract}

Keywords

Theory of education; critical pedagogy; philosophy of liberation; political education; Latin America (Source: Unesco Thesaurus). 


\section{Pedagogias criticas latino-americanas e filosofia da libertação: potencialidades de um diálogo teórico-político}

Resumo

Este artigo propõe um diálogo ético, político, epistemológico e conceitual de longo alcance entre a filosofia da libertação (elaborada por Enrique Dussel) e as pedagogias criticas latino-americanas. Preocupado em fortalecer as vertentes criticas que configuram o campo pedagógico, este texto se refere inicialmente às potencialidades teóricas de realizar um exercício dialógico entre as correntes indicadas. Além disso, reflete sobre os três grandes pontos de encontro ou de articulação: a práxis de libertação, o posicionamento da América Latina e as alteridades oprimidas, e a descolonização epistemológica. Finalmente, refere-se à relevância dos conceitos de libertação, alteridade e colonialidade para o futuro das pedagogias críticas latino-americanas do século XXI.

\section{Palavras-chave}

Teoria da educação; pedagogia crítica; filosofia da libertação; educação política; América Latina (Fonte: Tesauro da Unesco). 


\section{Potencialidades de un diálogo teórico-político}

Este artículo reflexiona sobre la pertinencia y relevancia de impulsar un proceso dialógico de largo alcance entre la Filosofía de la Liberación (particularmente desde la obra de Enrique Dussel) y las Pedagogías Críticas Latinoamericanas. Dicho diálogo nos permitirá profundizar al menos en dos aspectos.

En primer lugar, creemos que al reimpulsar procesos de diálogo y encuentro entre la filosofía y la pedagogía en general, y particularmente entre la Filosofía de la Liberación dusseliana y las Pedagogías Críticas Latinoamericanas, podemos avanzar, por un lado, en la superación de aquellas concepciones que reducen el campo pedagógico a aspectos técnicos, instrumentales y simplistas, las cuales, por lo menos desde la realidad chilena, han favorecido procesos de des-intelectualización, mecanización y banalización del trabajo pedagógico, es decir, podemos contribuir al refinamiento epistemológico, teórico y conceptual del campo pedagógico, y, además, podemos dotar de mayores grados de concreción y praxis al campo filosófico.' Desde nuestra perspectiva, tanto la Filosofía de la Liberación como las Pedagogías Críticas Latinoamericanas pueden ser fortalecidas a partir de dicho encuentro dialógico.

En segundo lugar, creemos que el ejercicio dialógico puede aportar en procesos de robustecimiento de "pedagogías otras", no elitizadas, infecundas ni ajenas a los sujetos, las comunidades y los pue-

$1 \quad$ Al respecto, nos parecen necesarias dos apreciaciones: una, para Ignacio Ellacuría, la Filosofía de la Liberación no ha logrado insertarse en una praxis liberadora. Esta debe pensarse desde, para y al servicio de los oprimidos, es decir, su abstracción y buenas intenciones deben pasar a ser eficazmente liberadoras (Samour, 2005).

Y dos, sobre la importancia de articular la Filosofía de la Liberación al campo pedagógico y educativo, nos parece pertinente reseñar las palabras del filósofo y educador popular uruguayo José Luis Rebellato, quien señaló: "La filosofía de la liberación encontrará, sin lugar a dudas, una fuente permanente de compromiso y de elaboración teórica en la educación popular liberadora. Ante todo, un lugar de compromiso, puesto que la filosofía de la liberación no es solo una elaboración teórica, sino una opción que implica la totalidad de la vida" (Rebellato, 1995, p. 205). blos oprimidos; "pedagogías otras" que reivindiquen la praxis liberadora, no contemplativa, sino críticopráctica, que sean capaces de poner al servicio de los movimientos sociales todo su caudal analítico, crítico y propositivo; "pedagogías otras" que, ancladas a las inquietudes y esperanzas de sus territorios, colmen de sentido popular y liberador sus horizontes de acción. Desde nuestra perspectiva, el fortalecimiento de estas "pedagogías otras" debe ser capaz de recoger y dialogar con todas aquellas abundantes y fructíferas vertientes sociocríticas del pensamiento latinoamericano.

En esta dirección, creemos que todos aquellos planteamientos teóricos, ético-políticos y metodológicos que permitan problematizar posiciones eurocéntricas, colonialistas, capitalistas, patriarcales, racistas, etc., deben ser capaces de entretejerse con las Pedagogías Críticas Latinoamericanas. Retomar aquellos caminos que nos encuentren con el marxismo latinoamericano, las teorías de la dependencia y el subdesarrollo, la Teología de la Liberación; la sociología liberadora y la investigación-acción participativa y militante; los planteamientos de la comunicación popular; las formulaciones teóricas del Grupo Modernidad/Colonialidad; y, por supuesto, con la Filosofía de la Liberación, es una tarea fundamental para nuestras pedagogías. Avanzar un poquito en ese encuentro, es una de las máximas pretensiones de este trabajo.

Para introducirnos en el ejercicio dialógico propuesto en este artículo, nos parece relevante presentar los derroteros históricos de cada una de estas corrientes emanadas desde Nuestra América. Una vez trazadas algunas notas introductorias en torno a la Filosofía de la Liberación dusseliana y las Pedagogías Críticas Latinoamericanas, nos detendremos a reflexionar sobre algunos puntos de encuentro que entrelazan los postulados éticos, epistemológicos y políticos de ambos proyectos. Para finalizar (a modo de apertura), nos detenemos en tres conceptos relevantes para el devenir de las Pedagogías Críticas Latinoamericanas en el siglo XXI: liberación, alteridad y colonialidad. 


\section{Notas introductorias a la Filosofía de la Liberación y la obra de Enrique Dussel}

\section{Sobre los origenes de la Filosofía de la Liberación}

Si bien el documento fundacional de la Filosofía de la Liberación fue elaborado en Argentina el año 1973 (y se encuentra firmado por los filósofos Osvaldo Ardiles, Hugo Assmann, Mario Casalla, Horacio Cerutti, Carlos Cullen, Julio De Zan, Enrique Dussel, Aníbal Fornari, Daniel Guillot, Rodolfo Kusch, Daniel Pro, Arturo Roig y Juan Carlos Scannone), los orígenes de la Filosofía de la Liberación en América Latina nos remontan a la década de los sesenta, fundamentalmente en un marco histórico regional signado por procesos de lucha contra el capitalismo dependiente, tardío y periférico, el imperialismo norteamericano y el colonialismo occidental. En este sentido, la Filosofía de la Liberación nació como heredera de los movimientos del '68, es decir, como sucesora de un complejo escenario de crisis política, económica, cultural y filosófica expresada en el Mayo francés, el Tlatelolco mexicano, el Cordobazo argentino, etc. (Romero, 2007; Dussel, Mendieta y Bohórquez, 2008).

Para autores como Enrique Dussel y Juan Carlos Scannone, la Filosofía de la Liberación emergió desde una generación de filósofos latinoamericanos, que planteando temáticas diversas, articularon sus postulados en torno a la denuncia de la filosofía occidental, europea, moderna, academicista. La Filosofía de la Liberación nació, entonces, como respuesta al proyecto imperial de la modernidad eurocéntrica. Parafraseando a Dussel, la Filosofía de la Liberación ha pretendido repensar la historia de la Filosofía, por un lado, desde la perspectiva del Centro-Imperial, es decir desde la filosofía moderna occidental que mediante un pensamiento ontológico ha deificado al ser y condenado a no ser al exterior (América Latina, Asia, África); y por otro, desde la perspectiva de la periferia mundial, pensando la realidad desde la exterioridad del ser del sistema (Dussel, 2011; Dussel, Mendieta, Bohórquez, 2008).
El filósofo argentino Horacio Cerutti rechazó profundamente el uso del concepto de generación para referirse a los orígenes de la Filosofía de la Liberación. Para el autor, dicho concepto adscribe a la historiografía liberal y supone cierta unidad en términos etarios e ideológicos, lo cual resulta completamente ajeno a la realidad del pensamiento filosófico argentino de los años sesenta. Para Cerutti, la Filosofía de la Liberación nunca ha sido un movimiento orgánico, ya que al interior de su campo se han desplegado abiertos, dinámicos y antagónicos debates (Cerutti, 2006).

Sin duda, la Filosofía de la Liberación se ha constituido como un proyecto intelectual de Latinoamérica, no solamente producido en la región, puesto que ha promovido un pensar autónomo de los centros de poder mundial, reconociendo el pensamiento latinoamericano desde la opresión y la dependencia. La Filosofía de la Liberación como filosofía latinoamericana nos invita recurrentemente a analizar sus postulados considerando las condiciones en que fueron producidos, sus determinaciones geopolíticas y las condiciones económicas, culturales e ideológicas a las que se encuentra supeditada.

Al surgir desde la periferia latinoamericana y al lograr articularse con las ciencias sociales, la Filosofía de la Liberación ha generado una ruptura epistemológica que la enlaza con las filosofías africanas y asiáticas. Interpelando a la filosofía occidental, pero sin desconocer su carácter hegemónico, se ha emparentado con los Estudios Subalternos y los Estudios Orientalistas, conformando así un conjunto de epistemologías fronterizas o epistemologías del sur, que reconocen su condición de subalternidad, pero que al recoger su propia experiencia histórica, cuestionan las estructuras dominantes y bosquejan posibilidades de superación (Mignolo, 2001).

Otros aspectos asociados a los orígenes de la Filosofía de la Liberación radican en la crítica al capitalismo central, en su opción por los pobres, oprimidos, explotados y marginados, y en su compromiso 
con la liberación integral de la humanidad (Infranca, 2000); en el empleo de las ciencias sociales como un pensamiento que posibilita situar y territorializar la reflexión filosófica (Brandani, 2008); y en su concepción geopolítica del conocimiento, es decir, entendiendo la Filosofía de la Liberación como un arma intelectual contra la explotación y la opresión de los pueblos, pero también como un proyecto intelectual de liberación de la filosofía (Mignolo, 2001).

\section{Primeras influencias teórico-políticas de la Filosofía de la Liberación}

A nivel latinoamericano, ejerció gran influencia en el surgimiento de la Filosofía de la Liberación la polémica entre el filósofo peruano Augusto Salazar Bondy y su colega mexicano Leopoldo Zea en torno al problema de la autenticidad y originalidad del filosofar en América Latina. En el texto ¿Existe una filosofía de nuestra América?, Salazar Bondy (2004) planteó que no ha existido una filosofía latinoamericana, ya que esta solo se ha limitado a acoger y repetir el pensamiento europeo. Latinoamérica, al ser una región cultural dependiente, subdesarrollada y alienada, solo habría producido una filosofía mistificada. Ahora bien, planteaba el autor, para poder construir una filosofía liberadora, se requería previamente romper con el sistema de dominación.

Leopoldo Zea respondió a los planteamientos de Salazar Bondy, argumentando que sí ha existido un auténtico pensamiento latinoamericano, y que dejar sus postulados de lado o desaparecerlos es una posición política nefasta. Para el mexicano, el pensamiento filosófico liberador nunca debe partir de cero, y por lo mismo se deben recoger las experiencias pasadas con responsabilidad y conciencia. Además, planteado en términos políticos, no resulta movilizador ni esperanzador tener que esperar a que nuestra cultura se libere para comenzar a pensar filosóficamente la liberación (Cerutti, 2006; Dussel, Mendieta y Bohórquez, 2008).

Junto al debate filosófico de Salazar Bondy y Leopoldo Zea, emergieron desde el pensamiento crí- tico y la teoría social latinoamericana al menos dos cuerpos teóricos centrales para la conformación de la Filosofía de la Liberación, nos referimos a las teorías de la dependencia y a la teología de la liberación.

Las teorías de la dependencia y el subdesarrollo, articuladas preferentemente por sociólogos, economistas e historiadores como André Gunder Frank, Rui Mauro Marini, Theodonio dos Santos, Aníbal Quijano, Franz Hinkelammert y Luis Vitale, otorgaron relevantes aportes a la Filosofía de la Liberación en torno a la caracterización del capitalismo periférico; las condiciones económicas, políticas e históricas de la dependencia y el subdesarrollo; el análisis de clase de las sociedades latinoamericanas; y la introducción de la teoría del intercambio desigual (Cerutti, 2006; Lowy, 2007; Dussel, Mendieta y Bohórquez, 2008).

Por su parte, la teología de la liberación, y particularmente la obra de Gustavo Gutiérrez, Leonardo Boff, Pedro Negre y Hugo Assman, también influyó en el desarrollo de la Filosofía de la Liberación. La teología de la liberación otorgó reflexiones fundamentales en torno a la incorporación de la utopía dentro del proceso histórico transformador, a la relevancia de la praxis transformadora comprometida con la humanización del mundo y al desarrollo de la noción de liberación (Cerutti, 2006; Lowy, 2007; Brandani, 2008).

Además, existieron otras líneas de pensamiento muy influyentes en la conformación de la Filosofía de la Liberación, entre las que destacan los planteamientos de la Escuela de Frankfurt, particularmente las obras de Herbert Marcuse y Ernst Bloch. Los argumentos de Marcuse, presentes en los libros El hombre unidimensional y Un ensayo sobre la liberación, que tuvieron mayor acogida en la intelectualidad Argentina, fueron el repudio al marxismo soviético, fortaleciendo el peronismo o la "tercera vía", el análisis de la ideología en las sociedades súper-industriales, las reflexiones sobre la utopía y la invalidación del proletariado como el sujeto de la revolución, re- 
cogiendo la importancia de la contra-cultura (Cerutti, 2006; García Ruiz, 2006).

Finalmente, durante la década de los setenta fue de gran importancia para los intelectuales latinoamericanos la obra del martiquinés-argelino Frantz Fanon, ya que representó el compromiso intelectual con los procesos de liberación del tercer mundo. Como sabemos, Fanon abordó desde la fenomenología los problemas del colonialismo y la opresión, categorías que serán retomadas por pensamiento sociocrítico de América Latina.

\section{Periodos de producción de la Filosofía de la Liberación dusseliana}

Uno de los principales referentes de la Filosofía de la Liberación, por su vasta producción intelectual, es Enrique Dussel. Su obra ha demostrado una considerable inquietud conceptual, por lo mismo, algunos de sus exégetas, como Eduardo Mendieta (2001), Pedro García Ruiz (2006) y Gildardo Díaz Novoa (2001), proponen abordar su producción ética, filosófica e histórica a partir de cuatro periodos. Así entonces, en coherencia con la literatura especializada y con la biografía del filósofo, podemos plantear los siguientes periodos para comprender su obra:

\section{De la ontología a la metafísica (1957-1975)}

Existe un primer momento de la producción filosófica de Enrique Dussel, remitido a su estadía en Europa, Medio Oriente e Israel (entre 1957 y 1966), donde fue profundamente influenciado por la ontología de Heidegger y la fenomenología de Husserl, Merleau-Ponty y Ricœur. ${ }^{2}$ Ahora bien, con su retor-

2 Entre los años 1961 y 1968, Dussel elaboró tres libros clave: El humanismo semita, El humanismo helénico y El dualismo en la antropología de la cristiandad. Situado en la tradición fenomenológica hermenéutica, Dussel intentó fundar una antropología filosófica que permitiera reconstruir la visión del mundo subyacente al ser latinoamericano (Dussel, 1999; García Ruiz, 2006).

Además de los textos mencionados, Dussel se doctora de Historia el año 1967 en la Universidad de La Sorbona con la tesis titulada El episcopado latinoamericano, institución misionera en defensa del indio (1504-1602) y un año antes, en 1966 publica el libro Historia de la Iglesia Latinoamericana. no a Argentina y particularmente a la ciudad de Mendoza el año 1966, Dussel comienza a empaparse de los planteamientos elaborados por el cristianismo de base, el Concilio Vaticano II, el Encuentro de Medellín, los planteamientos de los teóricos de la dependencia y los escritos de Fals Borda sobre la sociología de la liberación. En este contexto, el filósofo se interesa por profundizar en el pensamiento latinoamericano y por bosquejar supuestos de una filosofía liberadora.

Concretamente, el tránsito a la metafísica es realizado entre 1970 y 1974, cuando en conjunto con el filósofo español Xabier Zubiri, elaboraron un profundo estudio de la obra de Hegel que dará como resultado el libro La dialéctica hegeliana. En la segunda edición de este libro, titulada Método para una Filosofía de la Liberación, Dussel incorpora el concepto levinasiano de Exterioridad, entendido como aquello situado más allá de la totalidad del ser, más allá de la ontología (García Ruiz, 2006).

Levinas generó en Dussel una desorientación subversiva que lo llevó a desafiar su heideggerismo, y a rechazar el método dialéctico puesto que no daba cuenta de la alteridad. A partir de la metafísica levinasiana, Dussel elaborará el método analéctico o ana-dialéctico, y además incorporará las categorías de Exterioridad, Metafísica, Otro, etc. Con Levinas, el filósofo argentino cuestionó la ontología occidental, por reducir el Otro a lo Mismo, negando así la alteridad. Para Dussel, el otro levinasiano se concretiza en el indio empobrecido, el negro segregado, el judío exterminado, el asiático discriminado, la mujer objetualizada, el niño manipulado33 (Moreno Villa, 1999; García Ruiz, 2006).

3 Estos planteamientos están presentes en la primera ética dusseliana, concretizada en los libros: Para una Ética de la Liberación Latinoamericana, volumen I y II; Filosofía ética de la Liberación, volumen III; De la erótica a la pedagógica (el cual fue reeditado con el título Filosofía ética de la Liberación); Niveles concretos de la ética latinoamericana. Filosofía ética latinoamericana, volumen IV y la Filosofía ética latinoamericana, volumen $\mathrm{V}$. 
Cabe agregar que los planteamientos de Dussel superan y prolongan al menos tres aspectos del discurso filosófico de Levinas. En primer lugar, según Dussel, el filósofo lituano-francés sigue atrapado en la ideología dominante ya que solo piensa al Otro desde Europa, es decir desde los márgenes de la injusticia. Levinas no permite considerar a Latinoamérica como el Otro de la totalidad europea. El segundo aspecto que critica Dussel radica en el carácter aún abstracto del Otro levinasiano, ya que se omite su dimensión histórico-objetiva. Los/as pobres y oprimidos/as latinoamericanos/as son concretos/as. Finalmente, Levinas quedó estático frente al Otro, ya que no planteó el problema de la liberación, no cuestionó la praxis liberadora. La relación levinasiana con la otredad es quietista y contemplativa, no práxica ni transformadora (Moreno Villa, 1999; Dussel, 1999).

\section{De la metafisica al marxismo (1975-1990)}

El segundo momento de la obra del filósofo argentino se inscribe en la trayectoria que va de la metafísica al marxismo. Desde su exilio en México (1975), Dussel profundizará en análisis histórico sobre la exclusión, lo cual lo conducirá a la crítica al capitalismo y al mismo tiempo al estudio (no dogmático) de la obra de Karl Marx. La obra de Dussel en México puede dividirse en dos momentos: el del inicio, cuando sintetiza su trabajo realizado en Argentina y publica el libro Filosofía de la Liberación el año 1977,4 y posteriormente (entre 1977 y 1990), cuando se lanza a leer críticamente la obra de Marx (Sánchez Martínez, 1999).

La relación entre la Filosofía de la Liberación dusseliana y la obra de Marx ha poseído claramente dos momentos: el primero abiertamente antimarxista, presente en la obra Método para una Filosofía de la Liberación, y un segundo momento

4 El libro Filosofía de la Liberación perfiló una suerte de marco teórico al proyecto dusseliano de la filosofía de la liberación latinoamericana. Sus planteamientos sintetizan la trilogía antropológica escrita entre 1961 y 1968, y los cinco tomos de Para una ética de la liberación latinoamericana publicados entre 1970 y 1974. fuertemente marxista (Sánchez Martínez, 1999; Díaz Novoa, 2001).

El pensamiento dusseliano con respecto a Marx no es exactamente igual en todas sus etapas: hay un momento inicial en que rechaza radicalmente el pensamiento de Marx por considerarlo dentro de la llamada "ontología de la totalidad", concepto utilizado para caracterizar el pensar europeo como un pensamiento de la dominación, pero posteriormente en la medida en que se adentra en el conocimiento de esa forma de reflexión, aparece un acercamiento mucho más directo y original al extremo de considerarse a si mismo un marxista (Florian Cata, 2003, p. 1).

El Dussel antimarxista se engarza en el catolicismo tradicional de Mendoza y Argentina que optó políticamente por el peronismo. Durante las décadas de los sesenta y setenta, Dussel resaltó la incompatibilidad filosófica entre marxismo y cristianismo, pero sin distinguir los matices existentes entre el marxismo y la obra de Marx. Así, Dussel rechazó la dialéctica de Marx, la lógica de la Totalidad y la imposibilidad de pensar la alteridad del Otro. Cabe precisar que la acogida de la obra del filósofo judío Emanuel Levinas en América Latina, fue realizada por teólogos y filósofos interesados en la liberación, pero como alternativa teórica y política al marxismo. Por lo anteriormente expuesto, hasta el año 1977 Dussel consideró excluyentes las propuestas metodológicas de Marx y Levinas; sin embargo, paulatinamente, desde su exilio en México, comenzará a considerarlas complementarias (Sánchez Rubio, 1999; FornetBetancourt, 2001).

Según el propio Dussel, las inquietudes que lo aproximaron a la obra de Marx fueron la creciente miseria del continente americano y el brutal problema de la pobreza; la necesidad de efectuar una crítica al capitalismo, sistema responsable de la pobreza, la marginalidad y la exclusión; el interés por dotar de una filosofía económica y política a la Filosofía de la Liberación; y la urgencia de superar el dogmatismo 
marxista-leninista y afianzar la izquierda latinoamericana ${ }^{5}$ (Dussel, 1999).

\section{Del marxismo a la Ética de la Liberación mundial (1991-1999)}

Un tercer momento de su producción filosófica se despliega durante la década de los noventa, periodo asociado a procesos históricos como la crisis del "socialismo real", la hegemonía del proyecto neoliberal y el discurso globalizador, el auge de los planteamientos posmodernos y el "giro lingüístico" en las ciencias sociales, el predominio de aires desesperanzadores y acríticos en ciertos sectores de la intelectualidad de izquierdas; pero también a los albores de la rebelión zapatista en Chiapas.

En 1989, Dussel comienza a debatir con "filósofos del norte" tales como Karl-Otto Apel, Gianni Vattimo, Charles Taylor, Paul Ricœur y Richard Rorty. ${ }^{6}$ En general, Dussel acusó a los filósofos del Norte de encontrarse atrapados en la Modernidad eurocéntrica y en el capitalismo tardío de las sociedades opulentas; los culpó de adscribir al heleno-centrismo; los cuestionó permanentemente por carecer de reflexiones económicas, materiales, productivas; los interpeló por mantenerse atrapados en la totalidad sin lograr abrirse a las víctimas del sistema.

A partir del diálogo crítico con las filosofías del norte, Dussel elaborará una actualización de la Ética de la Liberación escrita en los años setenta, dando

5 La revisión dusseliana de Marx, realizada aproximadamente entre 1977 y 1990, dio origen a cuatro libros y otros textos. Los libros fueron: La producción teórica de Marx. Un comentario a los Grudrisse; Hacia un Marx desconocido. Comentarios a los escritos del 61-63; El último Marx (1863-1882) y la liberación latinoamericana y Las metáforas teológicas de Marx.

6 En 1989, Dussel comienza a debatir con Karl-Otto Apel; en 1991, con Ricœur y Rorty; en 1993, con Vattimo, y en 1996, con Habermas. El debate entre Karl-Otto Apel y Enrique Dussel se sintetiza en los libros: Fundamentación de la ética y la Filosofía de la Liberación y Debate en torno a la ética del discurso de Apel: diálogo Norte-Sur desde América Latina. El debate con Vattimo se encuentra en el libro Posmodernidad y Transmodernidad. Diálogos con la Filosofía de Gianni Vattimo. Finalmente, el debate con Ricœur y Rorty se encuentra en Apel, Ricceur, Rorty y la Filosofía de la Liberación. como resultado una segunda Ética de la Liberación. En esta segunda ética dusseliana, se desarrolla un importante giro que implica dejar de concebir a la Filosofía de la Liberación como latinoamericana, es decir regional o provinciana, apostando a situarse como una filosofía mundial (Dussel, 1998).

Además, la ética de la liberación dusseliana, fundamentada en la relectura de Marx, Luxemburgo, Gramsci, Bloch, Luckacs y Levinas, le permitió a Dussel argumentar sobre la necesidad de luchar por el reconocimiento de la voz de las víctimas (explotados/as, excluidos/as, negados/as) del sistema social. Así, la Ética de la Liberación "expresa una concepción del mundo que denuncia un modo trágico de ser, trágico por la carga de sufrimientos y de dolor que la condición humana soporta en la realidad latinoamericana y del tercer mundo" (Infranca, 2000, p. 109).

\section{Hacia una Filosofía Política de la Liberación (2001-actualidad)}

Para finalizar el apartado sobre las etapas de la obra de Dussel, creemos que desde el año 2001 a la fecha su producción filosófica se encuentra transitando un cuarto momento caracterizado por la elaboración de una filosofía política de la liberación. Los siguientes libros formarían parte del periodo actual al que nos referimos: Hacia una Filosofía Politica Critica (2001), 20 tesis de política (2006), Materiales para una Politica de la Liberación (2007), Política de la Liberación. Historia mundial y crítica (2007), Política de la Liberación. Arquitectónica, volumen II (2009), Carta a los indignados (2012).

\section{Apuntes en torno a las Pedagogías Críticas Latinoamericanas}

Afirmándonos en diferentes pedagogos latinoamericanos podemos sostener la existencia de Pedagogías Críticas que emanan desde nuestra realidad regional. Ahora bien, tal como señalaron los hermanos Nervi (2007) estas, más que ser un cuerpo teórico-práctico sistemático, central y unitario, 
ISSN 0123-1294 | Educ.Educ. Vol. 19. No. 1 | Enero-Abril de 2016 | pp. 67-88.

Universidad de La Sabana | Facultad de Educación

poseen un carácter múltiple, configurándose más bien como fragmentos teóricos, metodológicos y prácticos dispersos, polisémicos y variopintos (Puiggrós, 1998; Araújo, 2004; Pinto, 2007; Nervi y Nervi, 2007; Mejía, 2013).

En general, las investigaciones que han analizado las Pedagogías Críticas Latinoamericanas reconocen el carácter multifacético existente en su interior, donde se encuentran afluentes teórico-políticos de tipo democrático popular, socialista, marxista, libertario y cristiano, entre otras. Sin embargo, y a pesar de lo planteado, los análisis elaborados en torno al tema se han focalizado principalmente en la Pedagogía de la Liberación elaborada por el pedagogo brasilero Paulo Freire, deteniéndose con rigurosidad en análisis que avanzan desde su método de alfabetización hasta sus aportes filosóficos (Gadotti, 2003; Araújo, 2004). Hasta el momento nos parece un trabajo pendiente el abrir los análisis sobre las Pedagogías Críticas Latinoamericanas a otros autores que permitan aproximarnos a la complejidad de temas, perspectivas y posicionamientos de esta corriente pedagógica, y bosquejar un mapa aproximativo a los fundamentos filosóficos y núcleos problemáticos que las articulan y constituyen.

A pesar de la pluralidad y multiplicidad de teorías, metodologías y prácticas asociadas a las Pedagogías Críticas Latinoamericanas, existe concordancia bibliográfica acerca de una serie de elementos estructurales que le otorgan unidad. Al respecto parecen centrales temas tales como: 1) la naturaleza ética, política e ideológica de la educación, y la relevancia de la praxis político-pedagógica para la transformación social radical; 2) la identificación de factores alienantes y deshumanizantes en la cultura, por ende la educación entendida como proceso de concientización; 3) la necesidad de constituir espacios de autoeducación popular, "con"y "desde"los oprimidos y explotados; 4) la praxis dialógica como reconocimiento genuino - no instrumental ni formal- de los saberes populares subalternizados del Otro en tanto Otro; 5) la convicción de que la praxis pedagógica debe desarrollar y potenciar todas las facultades humanas, reivindicando las categorías de omnilateralidad e integralidad de la educación; 6) el reconocimiento del conflicto Norte-Sur y de los problemas del colonialismo y el eurocentrismo presentes en la pedagogía (Freire, 1973; Nassif, 1984; Rebellato, 1995; Rodríguez, 1997; Giroux y McLaren, 1998; Araújo, 2004; Aveiro, 2006).

Desde nuestra perspectiva, las Pedagogías Críticas Latinoamericanas residen por un lado en el pensamiento pedagógico contrahegemónico desplegado por pedagogos tales como Paulo Freire, Moacir Gadotti, Darcy Ribeiro, Gaudencio Frigotto, Demerval Saviani, Tomaz Tadeu da Silva (Brasil); Carlos Cullen, Carlos Alberto Torres, Roberto Follari, Adriana Puiggrós, Claudia Korol, Norma Michi (Argentina); Rolando Pinto, Hugo Zemelman (Chile); Iván Illich, Carlos Núñez, Roberto Abarca (México); Marco Raúl Mejía (Colombia); José Luis Rebellato (Uruguay), solo por nombrar algunos referentes contemporáneos. Pero por otro lado, habitan en la multiplicidad de experiencias de organización y lucha emanadas desde el movimiento popular latinoamericano, en los saberes constituidos por las organizaciones y los movimientos sociales, en la profunda memoria social del continente, en las identidades fragmentadas de nuestros pueblos y en las inagotables formas de creatividad y asociatividad popular. Con respecto a esto último, nos parecen relevantes los aportes realizados recientemente sobre la naturaleza pedagógica de las organizaciones y los movimientos sociales latinoamericanos realizados por Roseli Caldart (2012), Bruno Baronnet (2012), Norma Michi (2010) y la Universidad Intercultural Amawtay Wasi (2012).

\section{Historicidad de las Pedagogías Críticas Latinoamericanas}

Las reflexiones emanadas desde las Pedagogías Críticas Latinoamericanas, se despliegan en la realidad continental como el movimiento de un topo, es decir, emergen en el debate público de manera amplia y profunda en determinados momen- 
tos y coyunturas, para luego hundirse, invisibilizarse y recluirse al espacio íntimo de las experiencias y el trabajo cotidiano. A partir de este movimiento de emergencia e inmersión de proyectos educativos y pedagógicos coherentes con las necesidades, problemáticas y luchas latinoamericanas, el pedagogo colombiano Marco Raúl Mejía ha identificado cincos grandes troncos históricos, a saber:

1. Un primer tronco asociado en términos temporales a los procesos de emancipación del siglo $X I X$, recoge los planteamientos de los pensadores de la independencia, sobre todo los escritos de Simón Rodríguez y José Martí en torno a la creación de una educación que nos haga americanos y no europeos, creadores y no repetidores; que contribuya a liberarnos de mercaderes y clérigos; y que entregue herramientas para desarrollar un trabajo creativo y propio.

2. Un segundo momento asociado a la primera mitad del siglo XX y vinculado a la creación de universidades populares en Perú, El Salvador y México, planteó la necesidad de crear un proceso educativo coherente con los requerimientos de los trabajadores, que contribuyera a los procesos de concientización y que potenciara las organizaciones sindicales y culturales creadas por el movimiento obrero.

3. Como tercer tronco, y también asociado a la primera mitad del siglo $X X$, destaca el trabajo realizado desde las comunidades aymaras $y$ quechuas, sintetizado en la experiencia de la escuela Ayllu de Warisata. La propuesta, liderada por el pedagogo boliviano Elizardo Pérez, sostiene que deben configurarse prácticas educativas coherentes con la cultura de las comunidades indígenas; crear propuestas de educación como movimiento, es decir, que articulen la creación cultural con la transformación social; y asumir que la verdadera escuela se desarrolla articulada con la comunidad.
4. Un cuarto tronco histórico Mejía lo encuentra en la década de los cincuenta del siglo pasado, en la apuesta por construir escuelas desde los planteamientos de la educación popular, particularmente en la obra impulsada por José María Vélaz y el Movimiento Fe y Alegría (Colombia). Desde los planteamientos del grupo se sostiene la importancia de contribuir a los procesos de lucha popular contra la opresión y la desigualdad educativa, y la urgencia de promover cambios sociales desde una concepción integral de la educación popular.

5. Y finalmente, un tronco histórico asociado a la década de los sesenta del siglo XX, fuertemente influido por la Pedagogía de la Liberación, la Pedagogía del Oprimido, la Educación para la Emancipación y la obra de Paulo Freire. Además, en este periodo se configuraron cientos de alternativas de educación desde los movimientos sociales, la academia crítica y los grupos cristianos de base (Mejía, 2013).

Por su parte, la pedagoga argentina Adriana Puiggrós, también ensayó propuestas cronológicas para historizar a las pedagogías contrahegemónicas latinoamericanas. Para Puiggrós, existe un primer periodo que comprende la producción teórica y práctica del pedagogo venezolano Simón Rodríguez durante la primera mitad del siglo XIX. A su vez, existe un segundo periodo, desde la segunda mitad del siglo XIX y hasta la reforma universitaria de 1918, caracterizado por la existencia de prácticas y sentidos pedagógicos socialistas, anarquistas y democráticoespiritualistas. Un tercer periodo que se extiende desde 1918 hasta 1934, se caracteriza por la configuración de discursos pedagógicos nacionalistas populares asociados al irigoyenismo (Argentina), al aprismo (Perú) y el sandinismo (Nicaragua). Un cuarto periodo que va desde 1935 hasta 1955, caracterizado por la existencia de grandes discursos pedagógicos nacionalistas populares, estatales y de movimientos democráticos, tales como el cardenismo (México), el peronismo (Argentina), el varguismo (Brasil) y el 
Frente Popular en Chile. Un quinto periodo que se extiende desde 1959 con la Revolución cubana hasta 1975, caracterizado por grandes reformas educativas de carácter democrático-popular, el auge del movimiento estudiantil y el nacimiento y desarrollo de la Pedagogía de la Liberación. Finalmente, se identifica un sexto periodo entre 1976 y 1989, donde los discursos y proyectos pedagógicos producen prácticas y sentidos asociados a las luchas contra las dictaduras militares (Puiggrós, 1998 y 2010).

Concordando en lo medular con los planteamientos de Mejía y Puiggrós, el pedagogo chileno Rolando Pinto (2012) afirma que las Pedagogías Críticas Latinoamericanas no tienen sus inicios en la obra de Paulo Freire, sino en los escritos y prácticas del siglo XIX, particularmente con la obra del venezolano Simón Rodríguez. En palabras del pedagogo chileno:

El acumulado conceptual y metodológico de estas experiencias [desde el siglo XIX] es lo que genera un espacio teórico-práctico para que, en la realidad histórica y situacional de la educación, surja la alternancia de la educación popular crítica, base fundamental para que más tarde se articule la Pedagogía Crítica [Latinoamericana]. En esta base acumulativa, con todas sus expresiones creativas/criticas, de diversos educadores y educandos populares en cada país latinoamericano, sustentadas por grupos sociales y culturales del más diverso ámbito productivo y social, que van mostrando lo que somos y hemos sido en nuestro devenir histórico de pedagogos del cambio; se encuentra la fundamentación epistemológica y antropológica necesaria para la nueva educación democrática y liberadora para América Latina (Pinto, 2012, p. 49).

Así, entonces, concordamos con los planteamientos que sostienen que las Pedagogías Críticas Latinoamericanas son el resultado de todo un acumulado histórico de prácticas, conceptos, teorías y metodologías.

\section{Nudos constitutivos de las Pedagogías Críticas Latinoamericanas}

Nos parece interesante aventurarnos en el bosquejo de algunos nudos constitutivos de las Pedagogías Críticas Latinoamericanas. Desde nuestra perspectiva, las mismas se caracterizan al menos por cuatro nudos: son contrahegemónicas, territorializadas, emergentes desde la alteridad y configuradas desde la praxis. Debemos reconocer que cada uno de los elementos mencionados pueden dar cabida a inmensas investigaciones, sin embargo, nos basta con al menos dejarlos planteados.

\section{a) Pedagogías contrahegemónicas}

Cabe hacer notar que las Pedagogías Críticas Latinoamericanas, configuradas a partir de una multiplicidad de discursos y experiencias, han constituido un cuerpo pedagógico negado, excluido y deslegitimado por las pedagogías oficiales, puesto que precisamente se oponen de manera teórica y práctica a las diferentes formas de dominación existentes en sociedades capitalistas, patriarcales, racistas, adultocéntricas, etc. Ahora bien, además de oponerse a las relaciones sociales de dominación, las Pedagogías Críticas Latinoamericanas pretenden contribuir a la creación de prácticas socioeducativas que cuestionen y transformen la sociedad existente. Sus planteamientos se mueven entre la oposición y la proposición, entre la protesta y la propuesta o, como señaló Freire, entre la denuncia y el anuncio (Freire, 1990; Pinto, 2007).

En términos concretos, la posición contrahegemónica de las Pedagogías Críticas Latinoamericanas se ha expresado combatiendo aquellas concepciones que ocultan y obnubilan el carácter político de la educación; enfatizando sus vínculos con la cultura popular y los sujetos subalternos, arraigándose en las demandas de oprimidos/as y explotados/as; denunciando y resistiendo diferentes formas de control, segregación y exclusión; asignando relevancia al proceso de concientización con el impulso del pensamiento crítico y dialéctico; otorgando protagonismo a los su- 
jetos educandos en la práctica dialógica; y recuperando la centralidad de la praxis para la transformación social, comprometiéndose así con la reinterpretación y transformación popular de los procesos históricos (Freire, 1973 y 1990; Rebellato, 1995; Rodríguez, 1997; Giroux y McLaren, 1998; Mejía, 2013).

Cabe agregar que las Pedagogías Críticas Latinoamericanas, en tanto proyecto pedagógico contrahegemónico, avanzan más allá de la escuela y los procesos educativos institucionalizados, desplegándose en todas las esferas y dimensiones sociales. Son pedagogías que rompen con los muros de lo escolar y sus pretensiones de monopolizar la educación, ubicándose en un horizonte mucho más amplio, relativo al conjunto de relaciones sociales de carácter educativo que aseguran la reproducción/transformación del orden hegemónico (Mejía, 2013).

\section{b) Pedagogías territorializadas}

Un segundo nudo constitutivo de las Pedagogías Críticas Latinoamericanas radica en la importancia asignada a lo propio, lo local, lo situado, lo territorializado.? Dichas pedagogías apuestan a superar el pensar dependiente y eurocéntrico, desde un pensar histórico y geográfico, que valora y recupera lo propio, lo oculto y marginado por la racionalidad occidental moderna. Se trata así de reivindicar las particularidades de la experiencia latinoamericana; identificar las problemáticas y necesidades que atraviesan a la región; reconocer la creatividad

7 En este punto, nos parece particularmente relevante el concepto de geocultura articulado por Rodolfo Kusch, el cual establece una fuerte vinculación entre lo cultural y lo geográfico. Para el filósofo, todo pensamiento se constituye también por la gravidez del suelo. Será entonces el suelo, el territorio y su gravedad aquello que permitirá problematizar, deformar y corromper las nociones de "absoluto" y "universalidad" presentes en el pensamiento occidental. Pensar las pedagogías desde la gravidez del suelo, permite comprometernos con América Latina, con sus territorios, problemas, necesidades y deseos. Obviamente, asumir esta opción implica un compromiso y una disposición por (re)crearnos, rehacernos y reflexionar sobre qué somos y qué queremos ser, elaborando propuestas inmersas en las realidades geográficas y atadas a las problemáticas concretas de las comunidades (Kusch, 1976 y 1978). de un pensamiento situado y contextualizado sociohistórica y geográficamente; y potenciar un proyecto cultural y político que permita romper con siglos de colonialidad y eurocentrismo (Pinto, 2007; Puiggrós, 2010; Mejía, 2013).

A partir de la importancia de lo local y el territorio, las Pedagogías Críticas Latinoamericanas son proyectos que apuestan por articularse con experiencias, epistemes, subjetividades, movimientos que, ancladas a luchas sociohistóricas concretas, promueven lógicas cuestionadoras del poder hegemónico y superadoras del eurocentrismo. En este marco, se enredan en saberes populares, en economías solidarias y cooperativas, en teologías indígenas, en tecnologías propias, en formas de comunicación popular y alterativa, entre muchas otras. Así se trata, desde el campo pedagógico, de contribuir a los procesos de reconocimiento y autoafirmación de nuestros saberes, nuestras cosmogonías, nuestras epistemes, nuestras formas de vida (Puiggrós, 2010; Mejía, 2013).

A propósito de la pertinencia de potenciar pedagogías desde el territorio latinoamericano, nos parece interesante citar en extenso las palabras del pedagogo chileno Rolando Pinto:

A América Latina le urge pensarse desde otros lenguajes, desde otros contextos, rebelarse ante los paradigmas de la dominación, la reproducción y el control, de lo dado por las estructuras conceptuales que formalizan contenidos homogéneos. Hay que pensarla como continente que puede tener contenidos significantes abiertos a la multiplicidad, como horizonte posible para un nuevo movimiento gnoseológico, que reflexione en sí mismo, en un pensar no paramétrico. ¿Qué significa entonces el ser y estar de nuestra América? ¿Cómo descentrar los discursos para dar cuenta de la matriz cultural e histórica que subyace en cada espacio territorial? ¿Cómo desentrañar su subjetividad más profunda, aquella silenciada por la dominación, aquella que es potencia y posibilidad, aventura y apertura? (Pinto, 2007, p. 188). 
Las reflexiones de Pinto nos convocan a desarrollar un pensar auténtico, creativo, nuevo, capaz de articular categorías que nos permitan avanzar en procesos de ruptura y transformación, categorías situadas en la otra cara de la modernidad colonial, en la riqueza de la cultura popular, en lo bello y oculto de la América multicolor.

\section{c) Pedagogías de la alteridad}

Un tercer nudo constitutivo de las Pedagogías Críticas Latinoamericanas, que emerge enredado en los dos anteriores, radica en su opción ético-política por la alteridad, es decir por el/la Otro/a excluido/a, explotado/a, dominado/a. Desde esta perspectiva, los pedagogos críticos no podemos olvidar ni ignorar "la dignidad, que nos interpela como exterioridad, lo que está más allá de la esencia o de otro modo que ser, es decir: la justicia de la que somos responsables desde siempre" (Cullen, 2004, p. 130). Dicho posicionamiento ético-político, responsable del dolor y sufrimiento del Otro, impulsa al campo pedagógico a desarrollar procesos de aprendizaje del mundo y la realidad social, desde la injusticia, la explotación, la exclusión y también la esperanza, comprometiéndose con la interpelación de justicia y las luchas por la liberación de los sujetos oprimidos (Pinto, 2012).

Afirmarse en la alteridad del Otro, empuja a las Pedagogías Críticas Latinoamericanas a abrirse con respecto a la totalidad educativa hegemónica. Para superar la dominación opresiva se requiere una praxis abierta y dialogante desde y hacia el Otro. Solo en la visión del Otro se puede enfrentar la totalidad que genera el escenario donde el Otro sufre y es oprimido. "El otro es exterior a la totalidad y por sus condiciones de vida, que son tangibles a partir del contacto con su rostro, es posible entender su condición objetiva de sufrimiento" (Brandani, 2008, p. 28).

Posicionarse desde la materialidad del Otro, en las circunstancias políticas, sociales y económicas de la alteridad, nos permite reconocer la concreción del oprimido, identificar su rostro, voz, grito, pobre- za, etc. Solo conociendo y aproximándose a la realidad del Otro en cuanto Otro, las Pedagogías Críticas Latinoamericanas podrán avanzar en el reconocimiento de la pluralidad del territorio y en la configuración de comunidades otras, ajenas a las lógicas perversas de la dominación y la exclusión.

\section{d) Pedagogías de la praxis}

Un cuarto nudo constitutivo de las Pedagogías Críticas Latinoamericanas emana desde sus pretensiones transformadoras con respecto a la realidad histórica, concreta y material, y desde la crítica profunda a la racionalidad occidental moderna que escinde pensamiento y acción. En otros términos, las Pedagogías Críticas Latinoamericanas asumen que los procesos de liberación requieren algo más que la concientización de los sujetos, lo que implica avanzar también en términos prácticos hacia la transformación concreta de las estructuras de dominación.

Al posicionarse desde la praxis, las pedagogías contrahegemónicas pueden desarrollar, por un lado, procesos de develamiento y desnaturalización de la realidad opresora, configurando "actos problematizadores" de la existencia humana, que permitan profundizar en la concientización de los sujetos dominados. Y a su vez, pueden avanzar en la prefiguración de nuevas relaciones sociales, instituciones, acciones y discursos educativos que contengan en su seno las semillas de la liberación (Gadotti, 1996).

\section{Puntos de encuentro entre la Filosofía de la Liberación dusseliana y las Pedagogías Críticas Latinoamericanas}

Como señalamos en los primeros apartados del artículo, la Filosofía de la Liberación dusseliana y las Pedagogías Críticas Latinoamericanas, son corrientes que han tenido diferentes recorridos históricos, epistemológicos y disciplinares. Ahora bien, creemos que ambos poseen una gran cantidad de puntos de concordancia; poseen "algo en común" que los hace relacionarse como "compañeros/as", algo que 
los hace dialogar, no debatir, puesto que sus posiciones no son antagónicas ni adversarias, sino más bien cómplices. Reconociendo este compañerismo y complicidad, en el siguiente apartado abordaremos tres puntos de encuentro que nos parecen relevantes: la apuesta por configurar una praxis liberadora; el posicionamiento asociado al Sur, a Latinoamérica y al Otro oprimido; y la importancia de avanzar en la descolonización epistemológica.

\section{Primer punto de encuentro: praxis de liberación}

La Filosofía de la Liberación dusseliana, recogiendo los planteamientos del pedagogo brasilero Paulo Freire, señaló que la "praxis de liberación" es aquel entramado de acciones constantes que vinculan a los sujetos de una comunidad con la finalidad de transformar aquella realidad que los oprime y domina. La liberación como praxis se comprende como un acto transformativo humanizante de los/as oprimidos/as; ahora bien, resulta importante señalar que Dussel entendió la "praxis de liberación" no como un momento coyuntural asociado a revoluciones o grandes acontecimientos, sino a un proceso que se camina en lo cotidiano, en la vida ordinaria de todos los días (Dussel, 1998).

Los criterios y principios de injusticia, crueldad y opresión que se encarnan en acciones, en instituciones, en normas, en discursos, en sistemas de eticidad, son aquellos elementos que exigen e impulsan a la Filosofía de la Liberación y a las Pedagogías Críticas Latinoamericanas a seguir promoviendo el camino de la liberación. En ambos reside un horizonte liberador, un empuje a retomar senderos de lucha y organización que permitan a las comunidades y los sujetos vivir en dignidad y justicia.

La praxis de liberación juzga al sistema hegemónico desde su exterioridad, desde la vida de los/as Otros/as, desde la vida negada de los trabajadores asalariados o desempleados, desde la vida de las comunidades despojadas de sus tierras, etc.
La praxis de liberación no es funcional ni reformista del actual orden, sino más bien es radicalmente transformadora, productora y potenciadora de la vida humana (y planetaria). Desde la Filosofía de la Liberación dusseliana y desde las Pedagogías Críticas Latinoamericanas, se apuesta a tornar ilegítimo aquel orden dominante legitimado por formas de coerción y consenso, y se propone avanzar en la construcción de una nueva legitimidad, basada en nuevas acciones, nuevas normas, nuevas eticidades, nuevas instituciones.

La praxis de liberación arrastra consigo el "deber-ser" que impulsa a las alteridades oprimidas a luchar contra todas aquellas prácticas e instituciones que niegan su humanidad. La praxis liberadora exige acciones transformadoras por parte de la comunidad negada, obliga a transitar en procesos de organización, articulación y lucha mancomunada con el objeto de avanzar en los caminos de la rehumanización. Las contribuciones de la filosofía dusseliana y las Pedagogías Críticas Latinoamericanas pueden ser relevantes para fortalecer los lazos comunitarios que otorguen fuerza a las acciones liberadoras y para visibilizar críticamente tácticas y estrategias factibles para las transformaciones.

La Filosofía de la Liberación y las Pedagogías Críticas Latinoamericanas nos recuerdan con vehemencia que adscribir a la liberación como proyecto implica el deber de actuar creativamente en la historia, nos obligan a asumir las luchas para transformar la sociedad como una responsabilidad ineludible. Desde el paradigma liberador, si somos parte del bloque histórico de los/as dominados/as o de una comunidad de víctimas, debemos ser responsables ética y políticamente de la negación de la humanidad del Otro, por tanto, no podemos posicionarnos desde la indiferencia o el individualismo, debiendo actuar siempre cosolidariamente. Recogiendo los postulados del filósofo argentino-mexicano:

El que opera ético-criticamente debe (está obligado a) liberar a la víctima, como participante 
[...] de la misma comunidad a la que pertenecen las víctimas, por medio de a) una transformación factible de los momentos (de las normas, acciones, microestructuras, instituciones o sistemas de eticidad) que causan la negatividad material (impiden algún aspecto de la reproducción de la vida) o discursivo formal (alguna simetría o exclusión de la participación) de la victima; y b) la construcción, a través de mediaciones con factibilidad estratégico-instrumental criticas, de nuevas normas, acciones, microestructuras, instituciones o hasta sistemas completos de eticidad donde dichas victimas puedan vivir siendo participantes iguales y plenos (Dussel, 1998, p. 559).

Finalmente, la cita agrega un tema importante para aquellas disciplinas que adscriben al paradigma liberador: se trata del reconocimiento de los momentos negativos y positivos en la praxis de liberación. ${ }^{8} \mathrm{El}$ momento negativo al cual deben contribuir tanto la filosofía como la pedagogía consiste en deconstruir o destruir aquel sistema que es precisamente el responsable de la negación de la vida de ciertos sujetos y comunidades. Y el momento positivo, que se trata precisamente de la creación y construcción de prácticas, discursos, relaciones sociales, instituciones y eticidades que prefiguren la sociedad del mañana, que contengan en su seno las características constitutivas de una sociedad otra, que vayan desarrollando desde el ahora todos aquellos elementos y componentes que deseamos para el futuro.

\section{Segundo punto de encuentro: Latinoamérica y la alteridad oprimida}

En concordancia, creemos que tanto la Filosofía de la Liberación dusseliana como las Pedagogías Críticas Latinoamericanas emanan desde un lugar

8 Paulo Freire tiene interesantes reflexiones sobre el momento de la denuncia (momento negativo) y el anuncio (momento positivo) en el desarrollo práxico de una pedagogía liberadora. Desde nuestra perspectiva, los planteamientos dusselianos son muy próximos a los escritos del pedagogo brasilero (Freire, 1990). de enunciación común, el cual se articula geopolíticamente desde el Sur (particularmente América Latina) y subjetivamente desde la alteridad dominada. A partir de allí intentan comprender/transformar nuestras realidades y problemáticas, por lo tanto sus investigaciones, impulsadas y dinamizadas por la construcción de proyectos liberadores, pretenden contribuir a los procesos de subversión de todas aquellas estructuras responsables de la subalternización y dominación.

La Filosofía de la Liberación y las Pedagogías Críticas Latinoamericanas reconocen el carácter real, concreto, histórico y conflictivo del espacio planetario, del sistema-mundo moderno/colonial e identifican su emergencia precisamente con aquellos territorios dominados y periféricos. Nacen a partir del ejercicio de "tomarse en serio" el espacio geopolítico, reconociendo las implicancias de configurarse desde espacios marginales, subalternizados, subdesarrollados, colonizados. Se posicionan en el Sur, pero comprendido también como una metáfora del sufrimiento humano causado por la modernidad capitalista y colonial. El posicionamiento con y desde el Sur, permite fijar la mirada en las relaciones de poder, conflicto y dominación que se dan entre Norte/ Sur, para desde allí comenzar a reflexionar sobre los necesarios y urgentes procesos de resistencia y liberación (Santos, 2006 y 2009; Dussel, 2011; Mejía, 2013).

En coherencia con esta posición geopolítica, la Filosofía de la Liberación dusseliana y las Pedagogías Críticas Latinoamericanas, plantean su emergencia desde los/as dominados/as, oprimidos/as y explotados/as. En palabras del filósofo de origen mendocino:

Contra la ontología clásica del centro, desde Hegel hasta J. Habermas, por nombrar lo más lúcido de Europa, se levanta un contra-discurso, una Filosofía de la Liberación de la periferia, de los oprimidos, de los excluidos, la sombra que la luz del ser no ha podido iluminar, el silencio interpelante sin palabra todavía. Desde el no-ser, la nada, lo opaco, el otro, la exterioridad, el exclui- 
do, el misterio del sinsentido, desde el grito del pobre parte nuestro pensar (Dussel, 2011, p. 42).

Desde nuestra perspectiva, el posicionamiento ético-político de la Filosofía de la Liberación dusseliana y las Pedagogías Críticas Latinoamericanas, sustentado en el Sur, en América Latina, en el/la Otro/a oprimido/a, contiene un potencial crítico radical, en tanto: primero, permite deconstruir, cuestionar y negar aquellos discursos, prácticas, instituciones, relaciones, eticidades, etc., que emanan de los "centros de poder" del orden hegemónico, a partir de la otracara, el contra-discurso, lo negado, subalternizado y silenciado. Segundo, invita a construir un nuevo orden social, un nuevo proyecto histórico, basado en discursos-otros, prácticas-otras, nuevas formas de relacionarnos, instituciones-otras, eticidades-otras, etc., todo lo cual no debe esperar el "momento revolucionario", sino que debe emprender el camino de la praxis liberadora desde el hoy, desde la cotidianidad. Y tercero, interpela con fuerza a intelectuales (filósofos, cientistas sociales, pedagogos, etc.) a comprometerse en proyectos de transformación, cosolidarios y liberadores, a asumir la responsabilidad ineludible de ser comunidad humana, de movilizarse tras el grito de justicia del Otro negado/a.

\section{Tercer punto de encuentro: descolonización epistemológica}

Un tercer punto de encuentro entre la Filosofía de la Liberación dusseliana y las Pedagogías Críticas Latinoamericanas se asocia a la construcción de epistemologías otras, a partir del reconocimiento del carácter dominador del sistema-mundo capitalista y el pensamiento occidental moderno/colonial. Ambos proyectos reivindican una epistemología de resistencia, que emerge de la ruptura radical con los modos occidentales modernos de actuar y pensar, y se enfrenta al pensamiento monocultural de la ciencia moderna, sustentándose en el reconocimiento de una pluralidad de conocimientos heterogéneos, interconectados dinámicamente, entrecruzados (Santos, 2006 y 2009; Mejía, 2013).
Entre algunas de las críticas bosquejadas hacia el conocimiento racional, occidental moderno/colonial, podemos destacar las siguientes: en primer lugar, se considera incorrecto señalar que existe una distinción dicotómica entre ciencias naturales y ciencias sociales, puesto que la misma se sustenta en la dualidad hombre / naturaleza o cultura / materia, lo cual viene siendo refutado hace décadas por concepciones holísticas, complejas e integrales de la realidad. Para avanzar de la mano de la superación de la dicotomía entre ciencias naturales y ciencias sociales, se invita a realizar un acercamiento a las humanidades, superando todas las formas que adquiere el positivismo.

En segundo orden y en coherencia con lo planteado recientemente, se critica la dualidad entre sujeto/objeto establecida por el paradigma científico dominante. De acuerdo con una epistemología otra, la ciencia no descubre la realidad como sujeto externo a la misma, sino que crea la realidad y en esa acción creativa se conoce a sí mismo, lo que implica afirmar que todo el conocimiento científico es autoconocimiento. Se asume plena y explícitamente que el conocimiento científico debe ser íntimo y comprensivo, sin separarnos de aquello que estudiamos, contribuyendo a desarrollar de manera digna nuestras vidas individuales y comunitarias.

En tercer lugar, se rechaza la denostación realizada por la ciencia occidental moderna al sentido común. Si bien se reconoce el carácter mistificador y conservador del sentido común, también se señala que el mismo contiene una potencialidad utópica y liberadora basada en la acción, la practicidad y la creatividad, las que pueden fortalecerse en diálogo con el conocimiento científico. Así, se propone construir nuevas racionalidades mediante un ejercicio de inversión epistemológica, es decir, no se trata de superar el sentido común para llegar a un conocimiento científico, separado, aislado y superior, sino que se trata de convertir el nuevo conocimiento científico (liberador) en un nuevo sentido común (Santos, 2006 y 2009). 
La epistemología otra, en la que se entrelazan la Filosofía de la Liberación y las Pedagogías Críticas Latinoamericanas, reconoce y valora los saberes, quehaceres y prácticas del Sur que han ido constituyendo un campo distinto y antagónico al conocimiento racional, occidental, moderno y colonial. Estos saberes y conocimientos otros, encuentran sus soportes en contextos y territorios específicos y en comprensiones del mundo y formas de relacionamiento completamente diferentes a las occidentales. Es un entramado de saberes y conocimientos de frontera, constituidos en luchas, confrontaciones, diálogos culturales e interculturales (Santos, 2009; Mejía, 2013).

El intelectual portugués Boaventura de Sousa Santos entiende estas epistemologías otras (Epistemología del Sur) como una búsqueda de conocimientos otros y de nuevos criterios de validez de ese conocimiento, que permiten visibilizar y otorgar credibilidad a las prácticas cognitivas de los grupos, los pueblos y las clases que han sido excluidos, oprimidos, victimizados y explotados por el capitalismo y el colonialismo. Las epistemologías otras asumen que: 1) no puede existir justicia social y global sin recuperar y reconstruir conocimientos marginalizados y de resistencia; 2) no puede realizarse la superación del capitalismo sin romper con las actuales formas del colonialismo y viceversa; y z) se deben desarrollar formas de conocimiento que intensifiquen la voluntad para impulsar procesos de transformación social (Santos, 2009).

A lo planteado, cabe agregar que la propuesta epistemológica configurada desde la Filosofía de la Liberación dusseliana y las Pedagogías Críticas Latinoamericanas, intenta construir concepciones in tegrales sobre la realidad, acabando con dicotomías propias del pensamiento occidental moderno.

En esta crítica se plantea que es necesario buscar alternativas que ya existen en la cosmovisión de nuestros grupos amerindios, quienes desde siempre han planteado la unidad del universo y por lo tanto de lo humano y la naturaleza, lo cual da fundamento a la igualdad de la vida y por lo tanto entre los humanos, mostrándonos un mundo no fundado en el control humano de la naturaleza, sino la integralidad en ella de las diversas formas de vida. Para ello se apela a la tradición y se encuentra en el mundo quechua la idea de sumak kawsay (la vida en plenitudy armonía), en el mundo kuna baluwaba (la unidad de la naturaleza), y en el aymara el suma oamaña (el bienestar de tu fuerza interna) (Mejía, 2013, p. 212).

Solo recuperando tradiciones integrales de vida, como la del Buen Vivir, podremos avanzar hacia la construcción de formas sociales ajenas y superadoras del capitalismo: formas democráticas de carácter directo y participativo; formas integrales y saludables de relacionarnos con la naturaleza; formas horizontales y responsables de relacionarnos con el Otro negado y excluido (Mejía, 2013).

\section{Aperturas conceptuales: liberación, alteridad y colonialidad}

A partir de lo planteado a lo largo del artículo, y posicionando nuestro trabajo desde el campo pedagógico, creemos que el diálogo con la Filosofía de la Liberación dusseliana permite la apertura y profundización en al menos tres conceptos: liberación, alteridad y colonialidad. Siendo escuetos, al respecto solamente nos interesa señalar:

1. El concepto de alteridad contiene un enorme potencial crítico, en tanto permitirá superar aspectos del pensamiento ontológico occidental moderno, rompiendo la lógica cerrada de la totalidad y abriéndose a la radicalidad del Otro/a. La alteridad del Otro/a permite la irrupción de lo extra-ordinario, lo extra-sistémico, lo novedoso y lo transformador. La opción por la alteridad genera escenarios propicios para la irrupción de las eroticidades oprimidas, las culturas subalternizadas, las infancias y juventudes silen- 
ciadas, las comunidades excluidas, los sujetos explotados, los pueblos expoliados. El concepto y el posicionamiento desde la alteridad radical permitirá a las Pedagogías Críticas Latinoamericanas potenciar posiciones comprometidas y militantes, dispuestas a trabajar servicial y gratuitamente en procesos históricos con horizontes transformadores y liberadores.

2. El concepto de liberación (entendido como praxis, como principios o como proyecto), sujeta un horizonte de dignidad, justicia y libertad que las Pedagogías Críticas Latinoamericanas no deben olvidar para el siglo en curso. Posicionarse desde la liberación permitirá profundizar en procesos urgentes para las realidades latinoamericanas donde cotidianamente se recrean estructuras históricas que destruyen las posibilidades materiales y simbólicas de producir, reproducir y desarrollar la vida digna y justa de diferentes sujetos y comunidades. La vigencia de la liberación para las "pedagogías-otras" se sustenta en la necesidad de impulsar y promover transformaciones concretas y materiales en nuestras sociedades; en la importancia de negar y deconstruir aquellas normas, acciones e instituciones que generan la exclusión, la pobreza y el dolor; y en la importancia de prefigurar nuevos discursos, relaciones sociales, acciones e instituciones, que contengan desde hoy los elementos medulares de la sociedad del mañana.

3. El concepto de colonialidad (y su contracara, conocida como la decolonialidad), asociado a la crítica radical a la Modernidad occidental eurocéntrica, otorga también diversas posibilidades críticas al campo pedagógico. De hecho, desde hace por lo menos una década se vienen elaborando reflexiones teóricas que apuestan por desarrollar y potenciar pedagogías decoloniales y proyectos educativos sustentados en la interculturalidad crítica (Walsh, 2009; Fernández Mouján, 2009). Al posicionarse desde el concepto de colonialidad, las Pedagogías Críticas Latinoamericanas pueden andar caminos nuevos, desandando los supuestos epistémicos de la hegemonía europeo-norteamericana, y abriendo rutas para la construcción y el fortalecimiento de pensamientos otros, emergentes desde las voces, subjetividades, experiencias y memorias excluidas, opacadas e ignoradas por la modernidad eurocéntrica.

\section{Referencias}

Amawtay Wasi, Universidad Intercultural (2012). Aprender en la sabiduría y el buen vivir. Quito: Editorial UIAW.

Araújo, A. (coord.) (2004). La pedagogía de la Liberación en Paulo Freire. Barcelona: Grao.

Aveiro, M. (2006). La irrupción de la pedagogía de la liberación. Un proyecto ético-político de educación popular (Mendoza, 1973). Buenos Aires: Miño y Dávila Editores.

Baronnet, B. (2012). Autonomía y educación indígena. Las escuelas zapatistas de la Selva Lacandona de Chiapas, México. Quito: Editorial Abya Yala.

Brandani, A. (2008). Filosofía de la Liberación: Sus (nuevos) caminos. Historia-presente: propuestas de vida. Dos líneas: Rodolfo Kusch y Enrique Dussel. Tesis de Licenciatura en Filosofía, Universidad de Buenos Aires. 
ISSN $0123-1294$ | Educ.Educ. Vol. 19. No. 1 | Enero-Abril de 2016 | pp. 67-88.

Universidad de La Sabana | Facultad de Educación

Cabaluz, F. (2014). Filosofía de la Liberación y Pedagogías Críticas Latinoamericanas. Entrevista a Enrique Dussel. Cuaderno de Pensamiento Latinoamericano, (21), 136-148. Recuperado el 24 de octubre de 2014 de http:// www.cuadernoscepla.cl/web/wp-content/uploads/Texto-9_Fabi\%C3\%Arn-Cabaluz.pdf

Caldart, R.S. (2012). Pedagogia do Movimento Sem Terra. São Paulo: Editora Expressâo Popular.

Cerutti, H. (2006). Filosofía de la Liberación Latinoamericana. México D.F.: Fondo de Cultura Económica.

Cullen, C. (2004). Perfiles ético-politicos de la educación. Buenos Aires: Paidós.

Díaz Novoa, G. (2001). Enrique Dussel en la Filosofía Latinoamericana y frente a la filosofía eurocéntrica. Valladolid:Tesis doctoral Universidad de Valladolid.

Dussel, E. (1998). Ética de la Liberación en la edad de la globalización y la exclusión. Madrid:Trotta.

Dussel, E. (1999). Auto-percepción intelectual de un proceso histórico. Revista Anthropos, (180), 13-36.

Dussel, E., Mendieta, E. y Bohórquez, C. (eds.) (2008). El Pensamiento Filosófico Latinoamericano, Del Caribe y Latino (1300-2000). México: Siglo XXI Editores.

Dussel, E. (2011). Filosofía de la Liberación. México D.F.: Fondo de Cultura Económica.

Fernández Mouján, I. (2009). El rastro fanoniano en el concepto de liberación freiriano. Revista Pilquen, (6), 2-9. Argentina: Universidad Nacional de Río Negro.

Florián Cata, O. (2003). Filosofía de la Liberación y marxismo en la obra de Enrique Dussel. Revista Electrónica Cuba Siglo XXI. Recuperado el 24 de octubre de 2014 de http://www.nodo50.org/cubasigloXXI/congreso/ florian_10abro3.pdf

Fornet-Betancourt, R. (2001). Transformación del marxismo. México: Ediciones Plaza y Valdés.

Freire, P. (1973). Pedagogía del oprimido. Buenos Aires: Siglo XXI Editores.

Freire, P. (1990). La naturaleza política de la educación. Cultura, poder y liberación. Madrid: Paidós.

Gadotti, M. (1996). Pedagogía de la praxis. Buenos Aires: Miño y Dávila Editores.

Gadotti, M. (2003). Perspectivas actuales de la educación. Buenos Aires: Siglo XXI Editores.

García Ruiz, P. (2006). La Filosofía de la Liberación de Enrique Dussel: un humanismo del otro hombre. Recuperado el 19 de octubre de 2014 de http://www.ensayistas.org/critica/generales/C-H/mexico/dussel.htm

Giroux, H. y McLaren, P. (1998). Sociedad, cultura y educación. Madrid: Ediciones Miño y Dávila.

Infranca, A. (2000). El Otro Occidente. Buenos Aires: Editorial Antídoto. 
Kusch, R. (1976). Geocultura del hombre americano. Buenos Aires: Ediciones Fernando García Cambeiro.

Kusch, R. (1978). Esbozo de una antropología filosófica americana. Buenos Aires: Ediciones Castañeda.

Löwy, M. (2007). El marxismo en América Latina. Antología desde 1909 hasta nuestros días. Santiago de Chile: LOM Ediciones.

Mejía, M.R. (2013). Educaciones y Pedagogías Criticas del Sur (Cartografias de la Educación Popular). Santiago: Editorial Quimantú.

Mendieta, E. (2001). Política en la era de la globalización: Crítica de la razón política de Enrique Dussel. En Ingram, D. (coord.). Blakwell Readings in Continental Philosophy. USA: Blakwell Publisher.

Michi, N. (2010). Movimientos campesinos y educación. Estudio sobre el Movimiento de Trabajadores Rurales Sin Tierra de Brasil y el Movimiento Campesino de Santiago del Estero MOCASE-VC. Buenos Aires: El Colectivo.

Mignolo, W. (2001). Capitalismo y geopolítica del conocimiento. El eurocentrismo y la filosofía de la liberación en el debate intelectual contemporáneo. Buenos Aires: Ediciones del Signo.

Moreno Villa, M. (1999). Husserl, Heidegger, Levinas y la Filosofía de la Liberación. Revista Anthropos, (180), 47-58.

Nassif, R. (1984). Las tendencias pedagógicas en América Latina (1960-1980). En El sistema educativo en América Latina. Buenos Aires: Ediciones Kapelusz.

Nervi, M. L.y Nervi, H. (2007). ¿Existe la pedagogía? Hacia la construcción del saber pedagógico. Santiago de Chile: Editorial Universitaria.

Pinto, R. (2007). El currículum crítico. Una pedagogía transformativa para la educación latinoamericana. Santiago: Ediciones Universidad Católica de Chile.

Pinto, R. (2012). Principios filosóficos y epistemológicos del ser docente. San José: Coordinación Educativa y Cultural Centroamericana, CECC/SICA.

Puiggrós, A. (1998). La educación popular en América Latina. Orígenes, polémicas y perspectivas. Buenos Aires: Miño y Dávila Editores.

Puiggrós, A. (2010). De Simón Rodríguez a Paulo Freire: educación para la integración iberoamericana. Buenos Aires: Editorial Colihue.

Rebellato, J. L. (1995). La encrucijada de la ética. Neoliberalismo, conflicto Norte-Sur, liberación. Montevideo: Editorial Nordan-Comunidad.

Rodríguez, L. (1997). Pedagogía de la liberación y educación de adultos. En Dictaduras y utopía en la historia reciente argentina (1955-1983). Buenos Aires: Editorial Galerna. 
ISSN $0123-1294$ | Educ.Educ. Vol. 19. No. 1 | Enero-Abril de 2016 | pp. 67-88.

Universidad de La Sabana | Facultad de Educación

Romero, E. (2007). Solidaridad como parcialidad en la Filosofía de la Liberación de Enrique Dussel. En Figueroa, M. y Michelin, D. (comp.). Filosofía y Solidaridad. Santiago de Chile: Editorial Universidad Alberto Hurtado.

Salazar Bondy, A. (2004). ¿Existe una filosofía de nuestra América? México D.F.: Siglo XXI Editores.

Sánchez Martínez, L. (1999). Enrique Dussel en México. Revista Anthropos, (180), 87-90.

Sánchez Rubio, D. (1999). Filosofía, Derecho y Liberación en América Latina. Bilbao: Desclée de Brouwer.

Santos, B. S. (2006). Renovar la teoría crítica y reinventar la emancipación social (Encuentros en Buenos Aires). Buenos Aires: Clacso.

Santos, B. S. (2009). Una epistemología del Sur: la reinvención del conocimiento y la emancipación social. México. D.F.: Siglo XXI Editores y Clacso.

Samour, H. (2005). El significado de la Filosofía de la Liberación hoy. Cuadernos de Filosofía Latinoamericana, 26 (93), 130-147. Bogotá: Universidad Santo Tomás.

Walsh, C. (2009). Interculturalidad crítica y pedagogía decolonial: In-surgir, re-existir y re-vivir. En Vera, C. (ed.) (2009). Educaçao intercultural hoje en América Latina: concepçoes, tensoes e propostas. Río de Janeiro: PUC Educación on-line. 